\title{
Having One of the Fastest Growing Unmet Needs in Ophthalmology Reflected in Editorial Activities: Myopia
}

\author{
Kyoko Ohno-Matsui $^{\mathrm{a}}$ Hendrik P.N. Scholl ${ }^{\mathrm{b}, \mathrm{c}}$ \\ aDepartment of Ophthalmology and Visual Science, Tokyo Medical and Dental University, Tokyo, Japan; b Institute of \\ Molecular and Clinical Ophthalmology Basel (IOB), Basel, Switzerland; 'Department of Ophthalmology, University of \\ Basel, Basel, Switzerland
}

Myopia is a health concern worldwide. The prevalence of myopia has been increasing globally, and by 2050 it is estimated that about half of the world population will be myopic and $10 \%$ will be highly myopic (Fig. 1) [1]. Furthermore, due to an increase of time spent on near work and a decrease of outdoor activities in 2020 and 2021 as a result of the COVID-19 outbreak, this trend seems to be accelerated.

Although myopic eyes in general retain good best-corrected visual acuity, myopia is a risk factor for many blinding eye diseases, such as myopic macular degeneration, glaucoma, cataract, and retinal detachment [2]. In fact, an extrapolation of prevalence estimates of myopia in Singapore, the Republic of Korea, and Western Europe showed that by the years 2055 visual impairment will increase by 2 - to 3-fold in Europe, 3- to 5 -fold in Singapore, and even 3- to 6-fold in the Republic of Korea. Overall, it was concluded that myopia, or more precisely the associated risks of myopic macular degeneration, glaucoma, and retinal detachment, will become the most important cause of blindness [3].

karger@karger.com www.karger.com/ore

Karger!"

BOPEN ACCESS
C 2021 The Author(s).

Published by S. Karger AG, Basel

This article is licensed under the Creative Commons Attribution 4.0 International License (CC BY) (http://www.karger.com/Services/ OpenAccessLicense). Usage, derivative works and distribution are permitted provided that proper credit is given to the author and the original publisher.
The most serious form of myopia is known as pathologic myopia, which is defined by the presence of myopic maculopathy equal to or more serious than diffuse choroidal atrophy (category 2 according to META-PM classification [4]) or the presence of posterior staphyloma [5]. An increase of axial length usually occurs in the equatorial region of the eye in myopia; however, posterior fundus, including central nervous tissue like macular retina and the optic nerve, is damaged by eye deformity due to staphylomas in eyes with pathologic myopia.

Moreover, a recent study also showed that an axial elongation, which is expected to occur up to early adulthood, continues in later life in eyes with pathologic myopia, and the baseline axial length was correlated with further increase at older ages [6]. This suggests that preventing myopia progression in childhood and in young adults is important in many ways. Arresting axial elongation may also be necessary for patients with pathologic myopia throughout their life.

There have been great advances in the field of myopia research recently, including in genetics, animal models, human pathologies, and new treatments. Indeed, the

Correspondence to:

Hendrik P.N. Scholl, hendrik.scholl@ usb.ch 
Fig. 1. Global number of people estimated to have myopia and high myopia for each decade from 2000 through 2050. Replotted from Holden et al. [1].

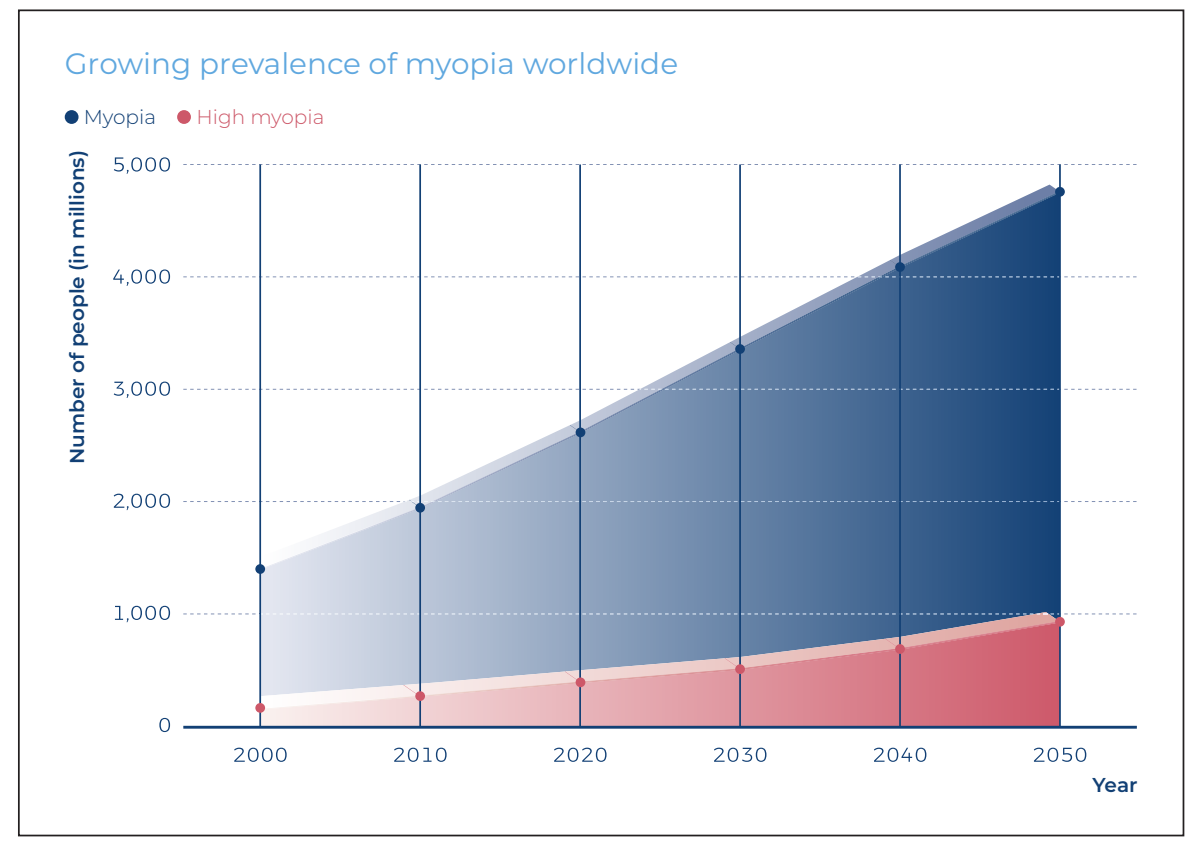

journal Ophthalmic Research has seen a steep increase in manuscripts in the field of myopia. Despite this trend, the major journals in our field that either issue companion journals (e.g., Ophthalmology) or have topic specific sections (e.g., Investigative Ophthalmology \& Visual Science, IOVS) do not yet cover myopia as a dedicated section. Ophthalmic Research, however, has now started a section on myopia and appointed Dr. Kyoko Ohno-Matsui as the Associate Editor of this section. Dr. Ohno-Matsui is Professor and Chairperson of the Department of Ophthalmology and Visual Science at Tokyo Medical and Dental University, and the Chief of the Advanced Clinical Center for Myopia at Tokyo Medical and Dental University. She has been a leader in the field of myopia and especially pathologic myopia. Dr. Ohno-Matsui established the international photographic classification of myopic maculopathy, and a new technique called "3D MRI of the eye" as a method to visualize the shape of the entire globe. She is actively working on ultra-wide field OCT imaging to visualize the full extent of staphyloma in many patients in vivo. Her lab also investigates the basic mechanisms of myopization and ocular angiogenesis.

The editorial board of Ophthalmic Research is honored to have Dr. Ohno-Matsui join as associate editor for our new section devoted to myopia. It will boost our activities to fulfill the journal's mission to be a premier resource of research in ophthalmology with the highest standards of originality and integrity.

\section{Conflict of Interest Statement}

Hendrik P.N. Scholl is the editor-in-chief of Ophthalmic Research.

\section{Funding Sources}

The authors declare no funding source.

\section{Author Contributions}

K.O.-M. and H.P.N.S. contributed equally to the writing of the manuscript.

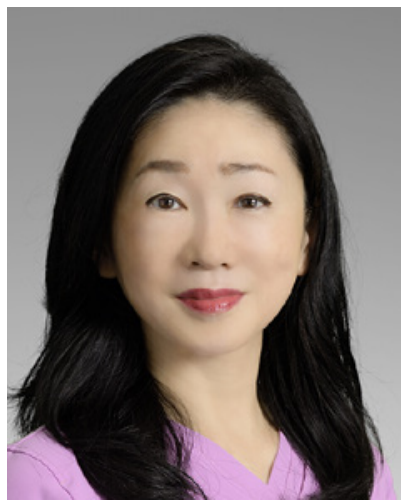

Kyoko Ohno-Matsui

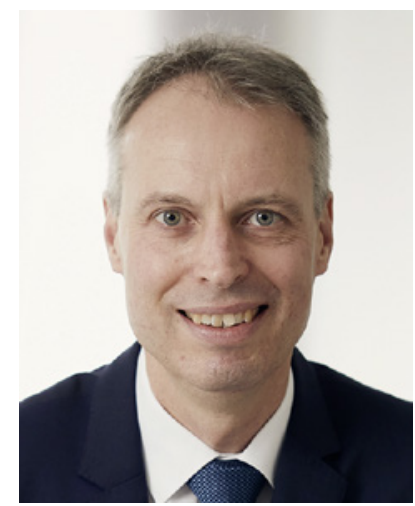

Hendrik P.N. Scholl 


\section{References}

1 Holden BA, Fricke TR, Wilson DA, Jong M, Naidoo KS, Sankaridurg P, et al. Global prevalence of myopia and high myopia and temporal trends from 2000 through 2050. Ophthalmology. 2016 May;123(5):1036-42.

2 Flitcroft DI. The complex interactions of retinal, optical and environmental factors in myopia aetiology. Prog Retin Eye Res. 2012; $31(6): 622-60$.
3 Tideman JW, Snabel MC, Tedja MS, van Rijn GA, Wong KT, Kuijpers RW, et al. Association of axial length with risk of uncorrectable visual impairment for Europeans with myopia. JAMA Ophthalmol. 2016;134(12):135563.

4 Ohno-Matsui K, Kawasaki R, Jonas JB, Cheung CM, Saw SM, Verhoeven VJ, et al. International photographic classification and grading system for myopic maculopathy. Am J Ophthalmol. 2015 May;159(5):877-33.
5 Ohno-Matsui K, Lai TY, Lai CC, Cheung CM. Updates of pathologic myopia. Prog Retin Eye Res. 2016 May;52:156-87.

6 Du R, Xie S, Igarashi-Yokoi T, Watanabe T, Uramoto K, Takahashi H, et al. Continued increase of axial length and its risk factors in adults with high myopia. JAMA Ophthalmol. 2021 Oct 1;139(10):1096-103. 